\title{
The Effectiveness of a Behavioral Training Program to Improve Joint Attention in Children with Moderate Intellectual Disability in Jordan
}

\author{
Ihsan Igdaifan Ali Alseraa ${ }^{1, *}$ \\ ${ }^{1}$ Al al-Bayt University, Jordan \\ *Correspondence: Al al-Bayt University, Jordan. Tel: 962-777-290-709 E-mail: \\ ahs119193@yahoo.com
}

Received: November 20, 2019 Accepted: December 17, 2019 Published: December 23, 2019

doi:10.5296/ije.v11i4.16225 URL: https://doi.org/10.5296/ije.v11i4.16225

\begin{abstract}
This study aimed to recognize the effect of a behavioral training program on the improvement of joint attention in children with moderate intellectual disability in Jordan, where the experimental method has been applied by single-case research design, and the researcher has prepared and applied the standard for joint attention in children with moderate intellectual disability, whose age ranged between (8-11 years)after indices of validity and reliability necessary for the scale has been calculated.

The number of individuals in the study sample is (20) child with moderate intellectual disability, who have been chosen from one of the centers for special education, which is specialized in rehabilitating, training and educating children with intellectual disability in Irbid province, where they had been chosen intentionally because the required conditions in the sample are met. Additionally, a behavioral training program has been applied to develop joint attention skills in children with moderate intellectual disability after indicators of validity, which are necessary for the program, has been calculated. Also, the study results showed that there are differences between the averages, in favor of the posttest design in the total score, where the average is (2.092) in the posttest design, which indicated that the program was effective in improving joint attention in children with moderate intellectual disability. Furthermore, the results showed that there are statistically-significant differences at significance level $(0.05=\alpha)$ in the total score for the standard, and in the dimensions included in the standard of joint attention, in favor of posttest design, where the difference between the two averages in the total score is( 0.356$)$ in favor of the posttest.
\end{abstract}

Keywords: moderate intellectual disability, joint attention, behavioral training program 


\section{Introduction}

In general, taking care of disabled children has started to go in the right direction in the last 10 years, not only in Jordan but also across the world, especially after 'convention on the rights of persons with disabilities' existed. The intellectual disability group is one of the groups, which has been given noticeable attention in terms of diagnosis, setting up various treatment programs, from which children with mild intellectual disability have benefited substantially. However, the group of children with moderate intellectual disability are still facing bigger challenges than those of children with mild intellectual disability, where the more the disability becomes severe, the more the problems associated with it increase whether in diagnosis, behavioral skills, or the basic psychological processes as well as in the services and treatment programs.

Children with moderate intellectual disability are in need of many requirements because intellectual disability is one of the developing disorders associated with many problems that differ in quality and quantity. Besides, it differs from a child to another. But there are some of the general qualities shared among most children with moderate Intellectual disability, such as qualitative failure in social, verbal and cognitive interaction and generally problems of attention skills, especially joint attention, which the failure in it is considered one of the major problems that teachers face when training and educating children with moderate intellectual disability.

\subsection{Problems and Questions of the Study}

Problem of the study was perceived by the researcher in the light of problem she noticed in the centers for children with moderate intellectual disability. These problems are consulted about by their teachers and parents in relation to the children's inability to generally pay attention to the skills during training and educating them, which causes many problems whose main cause is generally lack of attention, particularly joint attention, which makes the process of visual, auditory or motional communication difficult for children. Therefore, no interaction is achieved to acquire the skills, which are appropriately formulated.

Furthermore, lack of studies that dealt with developing and improving joint attention in children with moderate intellectual disability is one of the reasons behind dealing with this subject. Thus, the aim of this study is to recognize the effectiveness of a behavioral training program to improve joint attention in children with moderate intellectual disability in Jordan.

\subsection{The study Questions}

This study aims specifically to answer the two following questions:

- Are there any statistically significant differences at significance level $(0.05=\alpha)$ in children with moderate intellectual disability over improving joint attention skills in the pretest, posttest designs attributed to the behavioral training program?

- Are there statistically significant differences at significance level $(\alpha=0.05)$ in individuals of the study sample over joint attention skills in the posttest, follow-up designs?

\subsection{The Objectives of the Study}

This study aims to achieve the following objectives:

- Recognizing how effective the behavioral training program is in improving joint attention in children with moderate intellectual disability in Jordan. 
- Recognizing that the differences related to improving joint attention in children with moderate intellectual disability in Jordan in the pretest, posttest designs are attributed to the training program.

- Recognizing the differences related to improving joint attention in children with moderate intellectual disability in Jordan in the posttest, follow-up designs.

\subsection{The Importance of the Study}

Joint attention is considered as one of the basic skills, by which social interaction with others is achieved. Furthermore, lack of joint attention or failure initin children with intellectual disability causes them to waste a lot of communication and learning opportunities. In addition, possession of joint attention skills is generally considered essential to the communication process; so it is a must to care about the development and improvement of these skills, so here comes the importance of study to offer the researchers and the specialists working with children with moderate intellectual disability an explanation of the importance and necessity to focus their attention and efforts on improving joint attention, and its role in educating children and their possession of the required skills. Additionally, the study enriches the literature concerning this subject, and forms one of the main bases which could be relied on to formulate policies and plans, which would develop the services provided for children with moderate intellectual disability in the centers for private education. The development and improvement of services also needs finding solutions derived from specialized scientific studies. Moreover, the number of studies which dealt with joint attention in children with moderate intellectual disability in Jordan is too few, which increased the importance of conducting this study.

\subsection{The Limitations of the Study}

The study included the following ranges:

1.5.1 Human Limitation: the study is limited to (20) child with moderate intellectual disability in Jordan, their ages range from $(8-11)$ years.

1.5.2 Spatial limitation: the study was conducted on children with moderate intellectual disability joining Al-awj center for Intellectual disability and autism in Irbid province.

1.5.3 Time limitation: the study was conducted at the First semester of the year 2019/2020.

1.5.4 Subject limitation: the study was conducted to determine the effectiveness of a behavioral training program in improving joint attention in children with moderate intellectual disability in Jordan.

\subsection{Operational Definitions of Terms}

1.6.1 Behavioral training program: It is several training sessions, 25 in number, which achieve dimensions of the program, where every dimension is specialized in a specific aspect of skills. Furthermore, under every dimension comes (6) sub-skills, which would improve joint attention in children with moderate intellectual disability. Also, positive reinforcement method and modeling method were used to improve joint attention.

1.6.2 Children with moderate Intellectual disability: They are children who have been diagnosed by an official body in Jordan with a moderate intellectual disability, and joined centers for private education in Jordan.

1.6.3 Joint attention: It is the skills which represent the total score achieved by the examined 
through the tool prepared by the researcher.

\section{The Theoretical Framework and Literature Review}

\subsection{Theoretical Framework}

\subsubsection{Intellectual Disability}

The concept of Intellectual disability saw a series of developments in terminology; since these terms reflect different points of view of many scientific approaches, among of which the medical approach, psychological measurement approach, social approach, educational approach and other approaches. Many terms emerged like idiot, retarded, oaf, dumb and Intellectual disability. Recently, a new term has emerged from a lawyerly approach adopted by convention on the rights of persons with disabilities, i.e. the term 'Intellectual Disability' (Al khaldi, 2016).

The medical approach is regarded as one of the oldest approaches, which provided a definition of intellectual disability, in which it linked the definition to the causes, external aspects, and how healthy the nervous system is. Then terms emerged in reaction to the medical approach, which focuses on the causes leading to disability, and the inability of proponents of medical approach to give a quantitative description of mental ability, and the reliance of psychometric approach on psychological measurement process and intelligence standards, which give quantitative score that describes the mental ability. Then the social approach emerged, which relies basically on social validity, which is a standard through which a person can be judged to have an increase or decrease in his mental abilities. They deem a person mentally disabled if $\mathrm{s} /$ he fails to meet the social requirements. After that the educational approach emerged. It focused basically on attainment standard. A student is deemed mentally disabled if s/he couldn't communicate with their counterparts through language and writing and if s/he suffered a delay in their study for two or three years (Al-Quraiti, 2005)

The American Association on Intellectual and Developmental Disabilities (AAIDD) defines people with intellectual disability as people who have clear qualitative failure in mental performance below average with a standard deviation of 2 , which is accompanied by a failure in social adaptation, and appears prior to the age of 18 (al khaldi,2016).

The rate of spreading varies from society to another. Also, it increases or decreases according to a number of factors. The studies say that the known causes of Intellectual disability are estimated to be only (25\%), and (75\%) is attributed to unknown causes (Al-Rousan, 2001)

The causes can be divided into three main ones according to the period of time during which the case occurs:

- Prenatal causes: genetic factors, such as Down syndrome, and non-genetic factors like malnutrition, taking medicine and drugs, fall and shock.

- Perinatal causes: like obstructed labor

- Postnatal causes: such as shock, exposure to environmental pollution, diseases and tumors (Spence \& Kimberly, 2004).

Early diagnosis is essential to different disabilities, especially intellectual disability; so that treatment is provided soon. (Al-Qaryouti et al., 2001) indicate the misconception that 
diagnosis process is only an application of standardized intelligence test, and that this vision is narrow, and critical to assessment validity for reasons he sums up as follows:

- Intellectual disability is considered a multi-dimensional phenomenon. Additionally, these dimensions are overlapping, and the range of this overlap has not been recognized until now.

- There are many cases of Intellectual disability in which level of basic mental ability is higher than that of the apparent ability shown during test situation or when a child interacts with their counterparts.

- Most widespread standardized tests has been standardizedon samples of people with no intellectual disability without representing samples of mentally disabled people, so judging that there is a decrease in the mental ability of the examined in comparison with test standards is unfair.

\subsubsection{Joint Attention}

Significant joint attention skills are generally taught to disabled people and in particular to mentally disabled people. These skills are considered as vital, and develop since a child is born; because the more joint attention skills develop appropriately, the more the effect they have on establishing social pattern with others (Donna and Nancy, 2008).

Moreover, joint attention is considered necessary for verbal, social and cognitive development; because joint attention disorder will negatively affect the stimulation of social, cognitive and verbal interaction. Therefore, its development level will decrease. Joint attention does not only mean two people looking at the same object of interest but also means other skills, such as gaze alternation, pointing at a particular thing, initiating the need for something, and responding to others. Many specialists suggest that children with Intellectual disability suffer from lack of ability to respond properly to other people's bids, they are less likely to initiate joint attention, and it's harder for them to follow other people's eye gaze and the visual path. They also face difficulty in visual coordination with others. Joint attention is considered as a spontaneous engagement between two or more individuals by mental concentration on an external thing. Joint attention is more than just two people looking at the same thing. There is coincidence between participants to coordinate attention between this thing and the other person (Emily \& Edward, 2004).

Joint attention skill emerges generally in children prior to the age of (5) months. This skill develops as children get older and becomes more exchangeable and social. The initiation of joint attention develops directly after responding to it. Then declarative gesture behavior emerges. As the child grows older, and his/her verbal skills develop, non-verbal forms of joint attention are replaced by more verbal means to establish joint attention with others, in which the ability to trace the visual path and somebody else's eye gaze is considered one of the early elements to develop joint attention; since the ability to trace the eye gaze requires the child to be able to pay attention to all the existing things in the environment as well as human hint (Leekam \& Moore, 2000).

Joint attention is comprised of two main components: the response to joint attention, i.e. a child response to someone's bid to attract his/her attention, which is done through (head turning, gaze shifting and the ability to trace the visual path). The second component is the initiation of joint attention, i.e. the initiation on the child's part to attract someone's attention and initiating social interaction with another person, which is done through gesture, eye contact, or gaze alternation, where the reason behind the initiation is social participation. There are many indicators for the failure in joint attention in children, including the failure to 
trace someone's eye gaze, the failure to look at what other people are pointing at, lack of behavior towards pointing at things, not responding when calling them by their names, lack of spontaneous search for participating in the interests of others and not drawing other people's attention to subjects and surrounding events (Rebecca et al., 2008).

Many studies demonstrated that there is a close relationship between the failure in joint attention in children and the failure in their social interaction. This is explained in the light of that early failure in joint attention deprives those children of recognizing social information at an early stage. Consequently, this deprives the child of getting rewards or incentives as a result of early social exchanges, which in turn affects social interaction in those children (Boker, 2000).

\subsection{Previous Studies}

Omar (2018) conducted a study entitled "The effectiveness of a training program based on mutual attention in improving communication and some emotional aspects of a sample of autistic children, the study aimed to improve communication and some emotional aspects of a sample of autistic children through preparing a training program based on joint attention, then verify the effectiveness of the training program in improving communication and emotional aspects among autistic children, then know the continuity of the impact of the program after the follow-up period. Ten children with autism participated in the study with the Association of People with Special Needs in Al-Ahram Gardens in Giza Governorate, whose ages ranged between (5-7) years, and their intelligence level ranged between (58) and (78), and among them fourteen items of the autistic child scale, They were divided into two groups, one experimental and the other control, by five children in each group. The study used the Stanford Binet Test for Intelligence (fourth image), modified by Louis Kamel Malika 1998, the autistic child scale prepared by Adel Abdullah (2005), and the list of communication and emotional aspects of the autistic child prepared by the researcher, the results of the study indicated the presence of statistically significant differences at the level $(0.05)$ between the mean levels of the members of the experimental group on the communication list and the emotional aspects of the autistic child in both the pre and post measurements. And the presence of statistically significant differences at the level $(0.01)$ between the mean scores of the members of the experimental and control groups on the communication list and the emotional aspects of the autistic child in the post measurement. The results also indicated the absence of statistically significant differences between the mean scores of the members of the experimental group on the list of communication and the emotional aspects of the autistic child in both posttest and interactive test.

Abdel Hafez study (2014) aimed at improving joint attention in children with autism and its effect on developing verbal communication. The sample of the study consisted of 10 children with simple autism disorder, whose ages ranged between (4-7) years, and they were divided into two experimental and control groups, each of which includes 5 children, and homogenization took place between them was in terms of degree of intelligence, degree of autism, chronological age, economic and social level, skills of joint attention and verbal communication. The childhood autism assessment scale, the economic and social level, the verbal communication skills scale and the scale of improving joint attention were used. The results of the study verified the validity of all its hypotheses, which indicates the effectiveness of the program in improving verbal communication among autistic people.

Poon et al. (2013) conducted a study entitled "To What Extent Do Joint Attention, Imitation, and Object Play Behaviors in Infancy Predict Later Communication and Intellectual 
Functioning in ASD? This study is based on the assumption that shared attention, imitation, and play-by-play behaviors are associated with subsequent language and cognitive development in children with autism spectrum disorder, meaning that children who do not exhibit these behaviors are more likely to have mental and linguistic difficulties. The study used home videos for children who were subsequently diagnosed as autistic, and the goal is to measure levels of mutual attention and imitation, and play behaviors with things in addition to changing these levels over time. The researchers also tried to determine the extent to which idiosyncratic mental performance was associated with these children at the age of 3-7 years. The study was conducted on 29 autistic children. The results indicated that joint attention, imitation, and behavior of playing with things can predict communication and mental performance in children with autism spectrum disorder.

Al-Dahhan et al. (2011) conducted a study, which aimed to recognize the effectiveness of a training program that is based on motor and verbal expression to enhance attention and raise the level of safety for the child with an intellectual disability who has been abused and neglected. The sample of the study consisted of (24) child with minor Intellectual disabilities aged between (9-15 years old) in KSA. The study results showed attention improvement after applying the training program properly, and the study recommended developing a program that uses creative expression to improve psychological development of children with intellectual disabilities.

Amin (2010) also conducted a study that aimed to recognize the effectiveness of an early intervention program to develop joint attention skills among children with developmental disorders. The study sample consisted of (6) male children with autism at a specialized center for intellectual disability and autism in Egypt. The results showed the effectiveness of early intervention program that was applied to develop joint attention skills among these children, where its impact was shown in improving the level of social interactions among these children. Furthermore, the results emphasized the program's continues effectiveness until after the follow-up period.

Besides, Michelle et al. (2007) conducted a study that aimed to recognize the responsiveness of joint attention among pre-school children with developmental disorders through their interaction with their siblings in USA, where the study sample consisted of (51) child and some of their siblings. The study showed that there is a particular vulnerable joint attention, and this vulnerability affects their ability to interact socially, communicate verbally and play with others; they are in need of training programs for joint attention skills.

Al-Zyoot (2005) also conducted a study that aimed to recognize the effectiveness of a behavioral program in improving joint attention among children with minor intellectual disabilities enrolled at private education centers in Amman. The study sample consisted of (4) children that were selected among (91) child with intellectual disabilities. The study showed the improvement of attention level after exposing the children to training and follow-up scale after three weeks.

Aman (2000) conducted a study that aimed to recognize the effectiveness of a program for family treatment and behavioral strategies of children with attention disorders. The study sample consisted of (124) family divided into two groups, an experimental group and a control group. The study results showed attention improvement, development of skills needed for growth among children and improvement in parents' family satisfaction. 


\section{Method and Procedures}

This part dealt with describing the study population and sample, in addition to the tools used which its reliability and validity were verified, and the study variables were defined, as long with its procedures, and statistical treatment that was used to answer the study questions.

\subsection{Methodology}

The semi-experimental approach was used through using the one-group design with a pre and posttest, where the joint attention scale was applied to the study sample then the training program was applied on the experimental group then a post scale was done. Then, the pre and post responses of the study sample to the joint attention scale were compared according to the following design:
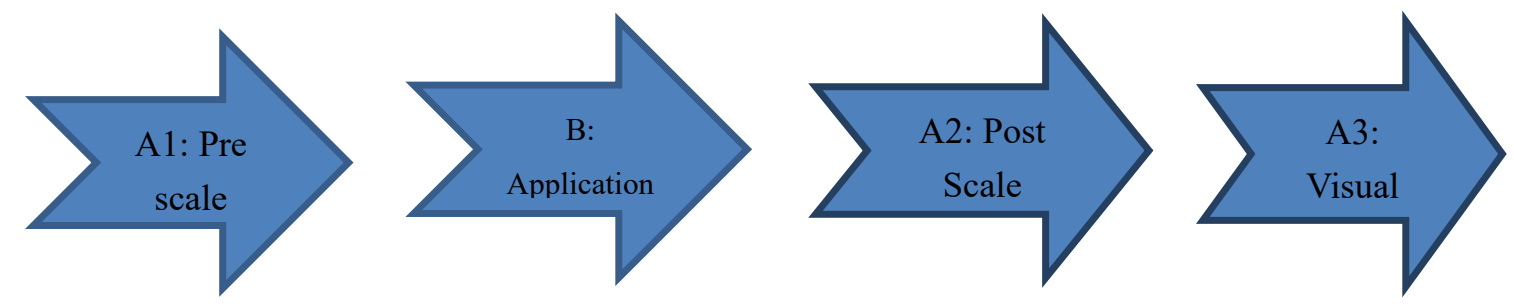

\subsection{Study Population and Its Sample}

The study population consisted of children with moderate intellectual disabilities in Irbid Governorate, where the study individuals were all children with moderate intellectual disabilities up to (20) child aged between (8-11) enrolled in Al-Awj Intellectual disability and Autism Center in Irbid Governorate.

\subsection{Study Instrument}

The researcher developed the joint attention scale for pre and post measurement. The scale was applied before and after training in order to identify the effectiveness of the behavioral training program. It was also applied to identify the tracking scale after applying the post scale over a period of (57) day, as the scale was designed gradually to identify the vulnerability and use of the study sample with regard to the joint attention skills correctly.

First: the researcher developed this scale in order to determine the joint attention skills among children with moderate intellectual disabilities as follows:

- Examine the literature review, studies, and researches related to the study subject.

- Review and examine some joint attention scales and its elements in order to draw upon.

- Formulate a draft scale that consisted of (5) dimensions, each dimension contains (6) paragraphs which are, visual communication, visual tracking, visual shift, visual audio communication, and motor visual communication.

- Formulate a final scale that consisted of (5) dimensions, each dimension contains (6) listed paragraphs on a 4 point Likert Scale (always, sometimes, seldom, never).

- Then, the validity indications were concluded through a content validity as the draft scale was presented to (10) arbitrators who are professors in special education major in order to ensure its suitability, the paragraphs' coherence with the dimensions, paragraphs' clarity, and the language; amendments that (80\%) of the arbitrators have agreed on were done. 
- The scale reliability indications were verified through internal consistency and test-retest reliability, where it was applied to (10) children with moderate intellectual disabilities aged between (8-11 years old) outside the study sample and two weeks later, the scale was re-applied. The correlation value according to Pearson coefficient has reached $(0.96)$ which is an appropriate significant correlation seen from Table 1.

Table 1. Test-Retest Reliability

\begin{tabular}{lllcc}
\hline Sample & N. & $\begin{array}{l}\text { Pearson } \\
\text { Correlation }\end{array}$ & Coefficient & Significance level \\
\hline First application & 10 & 0.96 & 0.00 \\
Second application & 10 & & \\
\hline
\end{tabular}

In order to find out the internal consistency's value, Cronbach's Alpha was used reaching (0.97) indicating a high level of reliability.

Second: training program of joint attention

The researcher developed a behavioral training program that aimed to enhance joint attention among children with moderate intellectual disabilities as follows:

- Considering the educational, psychological and scientific basis in terms of children with intellectual disabilities' needs to enhance joint attention, provide teachers of children with moderate intellectual disability, who teach and train them, with the most important modern and suitable strategies to enhance joint attention taking into account the transition from easiness to difficulty, the suitability of the program's content with the abilities of the children with moderate intellectual disabilities, and considering individual differences among children. In addition, the literature review and previous studies that discussed enhancing joint attention among children with intellectual disabilities were generally examined. Then, the training program draft was designed through:

- Determining the target group, which are the children with moderate Intellectual disabilities, aged between ( $8-11$ years old).

- Determining the general and sub objectives of the program.

- Designing sessions aiming to achieve objectives through determining the general objective of each session, and the sub objective of each general objective.

- Setting activities for each sub objective.

- Determining educational means and suitable enhancers for each objective.

- Determining behavioral techniques (positive enhancement, modeling) in each session.

- Determining the suitable place to apply each session.

- Setting executive procedures for each session to cover preparation, implementation, and ending a session

In order to find out the validity of the training program, the content validity method was used 
by presenting the training program to (10) teaching staff members in special education major. They were asked to arbitrate the behavioral training program for development of joint attention among children with moderate intellectual disabilities in terms of language, the suitability of the program in enhancing joint attention, the accuracy and validity of the sessions' procedures and how they are prepared and any other observations that need modification. Based on the arbitration results, the researcher has adjusted what $(80 \%)$ of the arbitrators have agreed on.

Afterwards, the final version of training program was made. Then the researcher applied several sessions of the training program as a trial in order to verify the validity of procedures for children with moderate intellectual disabilities through identifying the suitability of the various activities and techniques of the training program, identifying the appropriate way to use with the children with moderate intellectual disabilities during the program implementation, making sure of the possibility to apply the tools used in sessions and the checking appropriateness of time and place to implement the sessions.

\subsection{Study Procedures}

The study procedures were as follows:

First: limiting all special education centers that were licensed to receive children with intellectual disabilities in general.

Second: afterwards, the centers where the target study sample is enrolled in were limited based on the severity of the disability (moderate) and the age group. Al-Awj Intellectual disability and Autism Center was visited to obtain an approval in order to conduct the study, where an interview with the center director took place. The study purpose was explained briefly in addition to the procedures to be implemented and the training period, clarifying that the training will not affect the program used and applied in the center.

Third: three female teachers from the center were selected for the training that has long and adequate experience in the center. The female teachers were trained to the method of applying the behavioral training program through following the sequenced steps of training in each session. Furthermore, the tools and educational means for each session were provided.

Fourth: the participants were trained over three sessions:

The first session: explaining to the teachers the objective of the study, the qualities of students with moderate intellectual disabilities and answering any inquires by the teachers.

Second session: introducing the concept of joint attention, the theoretical background of the joint attention skills and the benefit of the training.

Third session: the behavioral training program was shown to the teachers and the method of applying each session along with the need to follow the sequenced steps of the training process. The researcher applied each training session in front of the teachers so they can understand what is needed exactly, and then he answered the teachers' questions regarding the training process.

Fifth: the pre-test was applied on the study sample.

Sixth: the training period lasted about two months, where a periodically follow-up took place through visits and phone calls. Through this visit, a follow up to the manner in which the training was presented to the teachers was done as well as participating in the training process 
of children with moderate intellectual disabilities.

Seventh: the post-test was applied and total marks of each child were calculated, where the pre- and post-marks were put in a table in order to conclude the results.

Eighth: after about two months of conducting the post scale, the follow-up scale was conducted in order to identify the difference between follow-up scale and post scale for the same study sample. The follow-up scale marks were put in a table to conclude results.

\subsection{Statistical Analysis}

To answer the study questions, the following was used:

- To answer the first question, the sub and total marks' arithmetic averages and standard derivations for the pre-and post-scales were calculated, and the Paired Samples T-test was used to calculate the significant differences between arithmetic means.

- To answer the second question, the arithmetic averages and standard derivations of the study sample responses to the sub dimensions and the total marks of joint attention scale were calculated, and the Paired Samples T-test was used to calculate the significant differences between arithmetic means.

\section{The Study Results}

This part dealt with results concluded by the study after applying the study tools and collecting and analyzing data. The results were presented according to the sequence of the study questions.

Results Related to the first question: Are there statistical significant differences at $(\alpha=0.05)$ among children with moderate intellectual disability in enhancing joint attention skills on the pre-and post-scales attributed to behavioral training program?

To answer this question, the arithmetic averages and standard derivations of the study sample responses to the scale dimensions pre and post training of the applied joint attention enhancement program were calculated, as shown in Table 2.

After reviewing the pre and post scale's athematic means of the total and the sub dimensions of the scale as illustrated in Table (2), it was shown that there are differences in favor of post scale, which indicates that the program was effective in enhancing joint attention among children with moderate intellectual disabilities. In addition, by reviewing the means of each dimension, it was shown that visual tracking dimension came first with an arithmetic mean of (2.19), and then the visual shift dimension came second with an arithmetic mean of (2.14). The visual audio communication came third with an arithmetic mean of (2.10), then, the visual communication dimension came fourth with an arithmetic mean of (2.04). Finally, the motor visual communication dimension came last with an arithmetic mean of (1.98). 


\section{Ml Macrothink}

Table 2. The Arithmetic Averages and Standard Derivations of the Study Sample Responses to the Joint Attention Scale's Dimensions and the Total Mark on the Scale

\begin{tabular}{llll}
\hline Paired sample & Dimensions & $\begin{array}{l}\text { Arithmetic } \\
\text { mean }\end{array}$ & $\begin{array}{l}\text { Standard } \\
\text { derivation }\end{array}$ \\
\hline \multirow{2}{*}{ Pair 1 } & Visual communication/before & 1.4969 & 0.46436 \\
& Visual communication/after & 2.0435 & 0.68946 \\
Pair 2 & Visual tracking / before & 1.3232 & 0.33328 \\
& Visual tracking / after & 2.1968 & 0.56811 \\
Pair 3 & Visual shift / before & 1.4832 & 0.41491 \\
& Visual shift/ after & 2.1406 & 0.43638 \\
Pair 4 & Visual audio communication / before & 1.6134 & 0.42998 \\
& Visual audio communication / after & 2.1001 & 0.59715 \\
Pair 5 & Motor Visual audio communication / before & 1.4260 & 0.35277 \\
& Motor Visual audio communication / after & 1.9837 & 0.56664 \\
Total & Before & 1.46854 & 0.36840 \\
& After & 2.09294 & 0.51786 \\
\hline
\end{tabular}

To calculate the significant differences between arithmetic means, Paired Samples T-test was used for each dimension shown in Table 3.

Table 3. The Results of Paired Samples T-test on Dimensions and the Total Mark of the Samples

\begin{tabular}{|c|c|c|c|c|c|c|c|}
\hline $\begin{array}{l}\text { Correlated } \\
\text { Pair }\end{array}$ & Dimensions & $\begin{array}{l}\text { Correlation } \\
\text { Coefficient }\end{array}$ & $\begin{array}{c}\text { Statistical } \\
\text { Significance of } \\
\text { the Correlation } \\
\text { Coefficient }\end{array}$ & $\begin{array}{l}\text { Arithmetic } \\
\text { Mean }\end{array}$ & $\begin{array}{l}\text { The } \\
\text { Difference } \\
\text { between the } \\
\text { two Means }\end{array}$ & $\begin{array}{c}\mathrm{T} \\
\text { value }\end{array}$ & $\begin{array}{c}\text { Statistical } \\
\text { Significance }\end{array}$ \\
\hline First Pair & $\begin{array}{c}\text { Visual } \\
\text { Communication } \\
\text { (Pre/Post) }\end{array}$ & 0.698 & 0.025 & $\begin{array}{l}\text { 1.4969Pre } \\
\text { 2.0435 Post }\end{array}$ & 0.5466 & 3.225 & 0.010 \\
\hline Second Pair & $\begin{array}{c}\text { Visual Tracking } \\
\text { (Pre/Post) }\end{array}$ & 0.742 & 0.014 & $\begin{array}{l}\text { 1.3232 Pre } \\
\text { 2.1968 Post }\end{array}$ & 0.8736 & 4.770 & 0.001 \\
\hline Third Pair & $\begin{array}{c}\text { Visual } \\
\text { Transformation } \\
\text { (Pre/Post) }\end{array}$ & 0.111 & 0.761 & $\begin{array}{l}\text { 1.4832 Pre } \\
2.1406 \text { Post }\end{array}$ & 0.6574 & 2.847 & 0.002 \\
\hline Fourth Pair & $\begin{array}{c}\text { Audiovisual } \\
\text { Communication } \\
\text { (pre/post) }\end{array}$ & 0.251 & 0.484 & $\begin{array}{l}\text { 1.6134 Pre } \\
\text { 2.1001 Post }\end{array}$ & 0.4867 & 3.144 & 0.012 \\
\hline Fifth Pair & $\begin{array}{c}\text { Motor } \\
\text { audiovisual } \\
\text { Communication } \\
\text { (pre/post) }\end{array}$ & 0.700 & 0.024 & $\begin{array}{l}\text { 1.4260 Pre } \\
\text { 1.9837 Post }\end{array}$ & 0.5577 & 4.125 & 0.002 \\
\hline Total & (Pre/Post) & 0.507 & 0.134 & $\begin{array}{l}\text { 1.4685 Pre } \\
\text { 2.0929 Post }\end{array}$ & 0.6244 & 3.785 & 0.004 \\
\hline
\end{tabular}


Table 3 shows that there are statistically significant differences at the significance level $(\alpha=$ 0.05 ) in the total score of the scale on the dimensions included in the joint attention skills scale in favor of the post-measurement, where the difference between the two means in the total score was (0.6244) in favor of the post-measurement which indicates a positive effect in favor of the post-measurement attributed to the joint attention training program for the study sample of children with moderate intellectual disabilities.

When sorting the dimensions in descending order based on the calculation of the difference between the arithmetic mean of the pre-measurement and the arithmetic mean of the post-measurement on each dimension, Table (4) shows that the Visual Tracking dimension ranked first, where the difference between the means of the pre and post measurements was (0.873) in favor of the post-measurement. The Visual Transformation ranked second, where the difference between the means of the pre and post measurements was $(0.657)$ in favor of the post-measurement. The Motor Audiovisual Communication ranked third, where the difference between the means of the pre and post measurements was (0.557) in favor of the post-measurement. The Visual Communication ranked fourth, where the difference between the means of the pre and post measurements was (0.546) in favor of the post-measurement. The Audiovisual Communication ranked fifth, where the difference between the means of the pre and post measurements was (0.486) in favor of the post-measurement.

Results related to the second question: Are there any statistically significant differences at the significance level $(\alpha=0.05)$ among the participants of the study sample in improving joint attention in the post and follow-up measurements?

To answer this question, the mean and standard deviations of the responses of the participants of the study sample were calculated in the joint attention scale.

Table 4. The Arithmetic Means and Standard Deviations for the Responses of the Study Sample Participants on the Joint Attention's Dimensions and Scale and the Total Score of the Scale in the Post and Follow-up Measurements

\begin{tabular}{llll}
\hline $\begin{array}{l}\text { Correlated } \\
\text { Pair }\end{array}$ & Dimensions & Arithmetic Mean & $\begin{array}{l}\text { Standard } \\
\text { Deviation }\end{array}$ \\
\hline First Pair & Visual Communication/Post & 2.0435 & 0.68946 \\
& Visual Communication/Follow-up & 1.8266 & 0.62085 \\
Second Pair & Visual Tracking/Post & 2.1968 & 0.56811 \\
& Visual Tracking/Follow-up & 1.4934 & 0.22939 \\
\multirow{2}{*}{ Third Pair } & Visual Transformation/Post & 2.1406 & 0.43638 \\
& Visual Transformation/Follow-up & 1.8601 & 0.57902 \\
Fourth Pair & Audiovisual Communication/Post & 2.1001 & 0.59715 \\
& Audiovisual Communication/Follow-up & 1.8520 & 0.56890 \\
Fifth Pair & Motor Audiovisual Communication/Post & 1.9837 & 0.56664 \\
& Motor Audiovisual Communication/Follow-up & 1.6520 & 0.37329 \\
Total & Total Post & 2.0929 & 0.51786 \\
& Total Follow-up & 1.73682 & 0.38831 \\
\hline
\end{tabular}


Table 4 shows the arithmetic means between the post and follow-up measurements for the total sum and the sub-dimensions of the scale. It shows that there are differences between them in favor of the post-measurement, which indicates that the program was not effective in maintaining performance after the participants of the study sample acquire the skills, as the differences in the means in the total score on the dimensions included in the joint attention skills in the post and follow-up measurements appear in favor of the post-measurement.

After sorting the performance of the participants of the study sample on the dimensions of the scale according to the arithmetic means of the follow-up performance, we found that the Visual Transformation dimension ranked first, where the arithmetic mean of the follow-up measurement was (1.860). The Audiovisual Communication dimension ranked second with an arithmetic mean of (1.852). The Visual Communication dimension ranked third with an arithmetic mean of (1.826) and the Motor Audiovisual Communication ranked fourth with an arithmetic mean of (1.652). The Visual Tracking dimension ranked the lowest with an arithmetic mean of (1.4934).

T-test for paired samples was used for each dimension to calculate the significance of the differences between the arithmetic means, and Table 5 shows this.

Table 5. The Results of the (T) Test for the Post and Follow-up Measurements on the Dimensions of the Scale and the Total Score

\begin{tabular}{|c|c|c|c|c|c|c|c|}
\hline $\begin{array}{l}\text { Correlated } \\
\text { Pair }\end{array}$ & Dimensions & $\begin{array}{l}\text { Correlation } \\
\text { Coefficient }\end{array}$ & $\begin{array}{l}\text { Statistical } \\
\text { Significance } \\
\text { of the } \\
\text { Correlation } \\
\text { Coefficient }\end{array}$ & $\begin{array}{l}\text { Arithmetic } \\
\text { Mean }\end{array}$ & $\begin{array}{l}\text { The } \\
\text { Difference } \\
\text { between } \\
\text { the two } \\
\text { Means }\end{array}$ & $\begin{array}{l}\mathrm{T} \\
\text { value }\end{array}$ & $\begin{array}{l}\text { Statistical } \\
\text { Significance }\end{array}$ \\
\hline First Pair & $\begin{array}{l}\text { Visual } \\
\text { Communication } \\
\text { (Post/Follow-up) }\end{array}$ & 0.994 & 0.000 & $\begin{array}{l}2.0435 \\
\text { Post } \\
1.8266 \\
\text { Follow-up }\end{array}$ & 0.216 & 6.08 & 0.01 \\
\hline $\begin{array}{l}\text { Second } \\
\text { Pair }\end{array}$ & $\begin{array}{l}\text { Visual Tracking } \\
\text { (Post/Follow-up) }\end{array}$ & 0.707 & 0.220 & $\begin{array}{l}2.1968 \text { Post } \\
1.4934 \\
\text { Follow-up }\end{array}$ & 0.703 & 3.83 & 0.004 \\
\hline Third Pair & $\begin{array}{l}\text { Visual } \\
\text { Transformation } \\
\text { (Post/Follow-up) }\end{array}$ & 0.815 & 0.004 & $\begin{array}{l}2.1406 \text { Post } \\
1.8601 \\
\text { Follow-up }\end{array}$ & 0.280 & 2.85 & 0.018 \\
\hline Fourth Pair & $\begin{array}{l}\text { Audiovisual } \\
\text { Communication } \\
\text { (Post/Follow-up) }\end{array}$ & 0.857 & 0.002 & $\begin{array}{l}\text { 2.1001 Post } \\
\text { 1.8520 Follow- } \\
\text { up }\end{array}$ & 0.248 & 4.28 & 0.002 \\
\hline Fifth Pair & $\begin{array}{l}\text { Motor } \\
\text { audiovisual } \\
\text { Communication } \\
\text { (Post/Follow-up) }\end{array}$ & 0.871 & 0.001 & $\begin{array}{l}1.9837 \text { Post } \\
1.6520 \\
\text { Follow-up }\end{array}$ & 0.331 & 2.95 & 0.015 \\
\hline Total & (Post/Follow-up) & 0.953 & 0.000 & $\begin{array}{l}2.0929 \text { Post } \\
1.73682 \\
\text { Follow-up }\end{array}$ & 0.356 & 5.88 & 0.00 \\
\hline
\end{tabular}


Table 5 shows that there are statistically significant differences at the significance level $(\alpha=$ 0.05 ) in the total score of the scale on the dimensions included in the joint attention scale in favor of the post-measurement, where the difference between the two means in the total score was $(0.356)$ in favor of the post-measurement, indicating that the skills that the participants of the study sample were trained on were not maintained.

When sorting the dimensions according to the calculation of the difference between the arithmetic means of the post and follow-up measurements on each dimension, it is shown in Table (5) that the Visual Tracking dimension ranked first, where the difference between the means of the post and follow-up measurements was (0.703) in favor of the post-measurement. The Audiovisual Communication dimension ranked second, where the difference between the means of the post and follow-up measurements was (0.331) in favor of the post-measurement. The Visual Transformation dimension ranked third, where the difference between the means of the post and follow-up measurements was (0.280) in favor of the post-measurement. The Audiovisual Communication dimension ranked fourth, where the difference between the means of the post and follow-up measurements was (0.298) in favor of the post-measurement. The Visual Communication dimension ranked the lowest, where the difference between the means of the post and follow-up measurements was (0.216) in favor of the post-measurement.

\subsection{Results Discussion and Recommendations}

This section discusses the results obtained, according to the sequence of the study questions, and lists the recommendations emanating from the study results.

First: Discussing the results related to the first question, which states: Are there any statistically significant differences at the significance level $(\alpha=0.05)$ among the participants of the study sample on the joint attention skills level in the pre and post measurements that are attributed to the training program?

The results related to this question, using the arithmetic means and standard deviations of the evaluations of the participants of the study sample on all dimensions of the joint attention scale, showed that there is a difference between the arithmetic means in favor of the post-measurement in the total score where the arithmetic mean was (2.092) in the post-measurement, which indicates that the program was effective in improving joint attention in children with moderate intellectual disabilities. The results were attributed to the fact that the general and sub-objectives of the program and its various sessions and activities and the application of the program sessions were appropriate in terms of choosing the place and methods used in the training program, in addition to the ability of the trained teachers. The program also included the provision of appropriate enhancements to the participants of the study sample after mastering the skills, which had a significant impact on the development of the performance of the study sample participants, in addition to those who implement the training program to develop and improve the joint attention who are experienced in training children with moderate intellectual disabilities and have undertook a specialized, accurate, and intensive training in the implementation of the program's sessions, all of which played a role in increasing the effectiveness of the program in improving the joint attention in children with intellectual disabilities.

The result of the current study were consistent with the results of Al-Dahhan et al (2011) study, and the results of Al-Zayoot (2005) study, and the results of Ali (1998) study, and the results of Qeshta (1995) study, but was inconsistent with the results of Amin (2010)study. 
Second: Discussing the results related to the second question, which states: Are there any statistically significant differences at the significance level $(\alpha=0.05)$ among the participants of the study sample in the joint attention skills in the post and follow-up measurements?

The results of the second question show that there are statistically significant differences at the significance level $(\alpha=0.05)$ in the total score of the scale on the dimensions included in the joint attention scale in favor of the post-measurement, where the difference between the two means in the total score was (0.356) in favor of the post-measurement, indicating that the skills that the participants of the study sample were trained on were not maintained. The researcher attributes this to the fact that the duration of the training was not enough to give the participants the joint attention skills and help them maintain those skills, as the duration of training was about two months, where the follow-up measurement was taken two months after the training program was completed and the post-measurement was taken. The researcher also believes that the impact of intellectual disability on developmental areas and on lowering intellectual abilities is also a major role in the lowered performance of the study sample participants in the follow-up measurement compared to the post-measurement. There are no studies whose results are consistent with those of the current study.

\subsection{Conclusion}

It is evident to us through the results of the current study and the results of previous studies that there is a clear effect of behavioral training programs on the joint attention of children with intellectual disabilities, Joint attention is more than just two people looking at the same thing, but there is a synchronization between the participants to coordinate attention between this thing and the other person, as joint attention has several skills that include eye contact, shifting eyesight, pointing to something and responding to the other, and any defect in these skills has an impact on the various aspects of development among children (cognitive, social, linguistic, and emotional), therefore, the presence of behavioral training programs that improves the level of joint attention, which positively affects the learning process, especially for children with intellectual disabilities.

\subsection{Recommendations}

In light of the findings of this study, the researcher recommends the following:

- Conducting more studies dealing with the joint attention skills for children with moderate and severe intellectual disabilities due to the lack of Arabic studies that deal with this subject.

- Holding training courses and workshops for teachers working with children with intellectual disabilities in general and moderate intellectual disabilities in particular, to introduce them to joint attention skills and their importance for children with intellectual disabilities.

- Making more training programs that could be used when training children with moderate intellectual disabilities to develop joint attention skills.

\section{References}

Abdel, H. H. (2014). Effectiveness of a program to improve joint attention in developing verbal communication skills among autistic children. Master Thesis, College of Education, Department of Special Education, University of Abn Shams. 
Al-khaldi, I. (2016). Teachers training needs who teach students with Mild intellectual disabilities who are integrated in public school in Jordan. Research on Humanities and Social Sciences, 6(12).

Al-Dahhan, M., Rushdie, S., \& Sahrawi, A. (2011). The Effectiveness of an Innovative Expression Program in Improving Attention and Psychological Security in a Child with Mental Retardation who is Abused and Neglected. Journal of Psychological Counseling, $28,20-61$.

Al-Qaryouti, Y., Sartawi, A., \& Smadi, J. (2001). Introduction to Special Education. Dubai: Dar Al Qalam Publishing \& Distribution.

Al-Quraiti, A. (2005). The Psychology of Individuals with Special Needs and their Education, 4. Cairo: Dar Al-Fak Al-Arabi.

Al-Rousan, F. (2001). A Comparative Study between the Performance of Ordinary and Mentally Disabled Students on a Modified Jordanian Form of Measuring Numerical Concepts. Journal of Social Sciences, 16(1), 98-121.

Al-Zayoot, F. (2005). The Effectiveness of a Behavioral Program in Improving Attention in Children with Mental Disabilities. Master Thesis, Faculty of Graduate Studies, University of Jordan.

Aman, L. (2000). Family System Multi-Group Therapy for ADHD Children and Their Families. Dissertation Abstracts International, pp.55489 (B).

Amin, S. (2010). The Effectiveness of an Early Intervention Program in Developing the Joint Attention for Autistic Children and its Effect on Improving the Level of Social Interactions. Unpublished Study, Alexandria University, Egypt.

Boker, M. (2000). Incorporating the Thematic Ritualistic Behaviors of Children with Autism into Games Increasing Social Play Interactions with Siblings. Journal of Positive Behavior Inter-venations, 2, 66-84. https://doi.org/10.1177/109830070000200201

Donna, S., \& Nancy, A. (2008). The Relationship Between Joint Attention and Language in Children With Autism Spectrum Disorders, Focus on Autism and Other Developmental Disabilities, 23(1), 5-1. https://doi.org/10.1177/1088357607311443

Emily, A., \& Edward, G. (2004). Joint Attention in Children with Autism: Theory and Intervention. Focus on Autism and Other Developmental Disabilities, 19(1), 13-26. https://doi.org/10.1177/10883576040190010301

Leekam, S., \& Moore, E. (2000). Targets and Cause: Goze Following in Children with Autism. Journal of Child Psychiatry, 39, 951-982. https://doi.org/10.1111/1469-7610.00398

Michelle, S. (2007). Sample Screen to Detect Toddlers at Risk of children: Check, Rolling Painting, Joint Attention. Family Practice News, 34(8), 91.

Omar, A. (2018). Conducted a Study Entitled "The effectiveness of a training program based 
on mutual attention in improving communication and some emotional aspects" of a sample of autistic children. Journal of Educational Sciences, 4.

Poon, K., Watson, L., Grace, B., \& Poe, D. (2013). To What Extent Do Joint Attention, Imitation, and Object Play Behaviors in Infancy Predict Later Communication and Intellectual Functioning in ASD? Journal of Autism and Developmental Disorders, 42, 1064-1075. https://doi.org/10.1007/s10803-011-1349-z

Rebecca, M., Jennifer, A., William, V., Amy, G., \& Gina, G. (2008). Behavioral assessment of Joint Attention. A Method-logical Report, 27(2), 138-150. https://doi.org/10.1016/j.ridd.2004.09.006PMid:15979843

\section{Copyright Disclaimer}

Copyright for this article is retained by the author(s), with first publication rights granted to the journal.

This is an open-access article distributed under the terms and conditions of the Creative Commons Attribution license (http://creativecommons.org/licenses/by/3.0/). 